\title{
New treatments in the management of type 2 diabetes: a critical appraisal of saxagliptin
}

This article was published in the following Dove Press journal:

Diabetes, Metabolic Syndrome and Obesity:Targets and Therapy 7 May 2010

Number of times this article has been viewed

\section{Baptist Gallwitz \\ Dept Medicine IV, Tübingen University, Otfried-Müller-Str, I0, 72076 Tübingen, Germany}

Correspondence: Baptist Gallwitz Dept Medicine IV,Tübingen University, Otfried-Müller-Str, 10, 72076 Tübingen, Germany

Tel +49 707I 2982093

Fax +49 707I 295004

Email baptist.gallwitz@med.

uni-tuebingen.de

\begin{abstract}
Saxagliptin is a novel dipeptidyl peptidase-4 inhibitor (DPP-4 inhibitor) for the treatment of type 2 diabetes, with a duration profile for once daily dosing. It is highly selective for DPP-4 in comparison to other enzymes of the dipeptidyl peptidase family. DPP-4 inhibitors elevate plasma concentrations of the incretin hormones glucagon-like peptide-1 (GLP-1) and gastric inhibitory polypeptide (GIP). This effect results in a glucose-dependent stimulation of insulin secretion and an inhibition of glucagon secretion without an intrinsic risk for hypoglycemia. In comparison to sulfonylureas and thiazolidinediones that promote weight gain, DPP-4 inhibitors are weight neutral. Saxagliptin has been approved by the FDA for the US and by the EMEA for Europe in 2009. Clinical trials showed a dose-dependent inhibition of DPP-4 by saxagliptin in doses ranging from 2.5 to $100 \mathrm{mg}$ daily without serious side effects. Type 2 diabetic patients receiving $5 \mathrm{mg}$ to $10 \mathrm{mg}$ saxagliptin once daily had a significant lowering of $\mathrm{HbA}_{1 \mathrm{c}}$ and glycemic parameters along with good tolerability and safety. Saxagliptin has demonstrated a good efficacy for glycemic parameters in various patient populations either in monotherapy or in combination with metformin and other oral antidiabetic drugs as well as a favorable cardiovascular profile. With its high selectivity for DPP-4 and its clinical and cardiovascular profile, saxagliptin is an attractive novel DPP-4 inhibitor.
\end{abstract}

Keywords: type 2 diabetes, diabetes therapy, DPP-4 inhibitors, incretin based therapy, GLP-1, saxagliptin

\section{Introduction}

The prevalence of type 2 diabetes is increasing dramatically worldwide. Estimations by the International Diabetes Federation (IDF) forecast the total number of people with diabetes to be 440 million worldwide by the year $2030 .{ }^{1}$ The increase in type 2 diabetes prevalence will inevitably lead to an increase of the complications and comorbidities of this disease. Efficacious and safe treatment options for type 2 diabetes are needed to prevent hypoglycemia and diabetes-related complications.

The pathophysiology of type 2 diabetes mainly comprises two phenomena: insulin resistance and a disturbance of insulin secretion. While insulin resistance is fairly constant in the time course of type 2 diabetes, the disturbance in insulin secretion worsens during the course of the disease due to continuously declining islet function. Decreasing islet function is the driving force for type 2 diabetes disease progression. This development is aggravated by chronically persisting hyperglycemia, elevated plasma concentrations of free fatty acids, cytokines, adipokines and toxic metabolic products that are detrimental for islet function and finally lead to a loss of beta-cell mass. The glucagon-secreting alpha cells in the islet additionally develop a 
secretory defect. In nondiabetes people, glucagon secretion is suppressed during hyperglycemia, but in type 2 diabetes subjects glucagon secretion during hyperglycemic conditions does not become suppressed. The relative hyperglucagonemia is possibly causal to the excessive glucose production by the liver observed in type 2 diabetes. $^{2-5}$

The older treatment options for type 2 diabetes are limited and do not address the problem of islet-cell dysfunction. Classical insulin secretagogues (sulfonylureas and glynides) exclusively act on the beta-cell and stimulate insulin secretion, but do not address the secretion defect of the alpha cells. Metformin and thiazolidinediones have a beneficial influence on insulin resistance, but have important contraindications. These are impaired renal function for metformin and heart failure for thiazolidinediones. The therapy with thiazolidinediones leads to an undesired gain in body weight. Alpha-glucosidase inhibitors delay the breakdown of complex carbohydrates and therefore act mainly on postprandial metabolism. With insulin therapy, a relative lack of insulin can be replaced and the endogenous secretory insulin deficit can be overcome, but insulin therapy is associated with a risk for hypoglycemia and weight gain. The increasing loss of islet function characterizing type 2 diabetes is not ameliorated by any of the classical treatment option. ${ }^{2-5}$

In the past few years, incretin-based therapies have become available offering promising ways to overcome the limitations of the classical treatment options for type 2 diabetes described above.

The incretin hormones glucagon-like peptide-1 (GLP-1) and glucose-dependent insulinotropic peptide (GIP) are secreted after a meal from the intestinal L- and K-cells respectively and physiologically stimulate insulin secretion postprandially. They are responsible for the incretin effect that described the phenomenon that orally ingested glucose evokes a greater insulin response than an intravenously administered glucose infusion calculated to lead to identical serum glucose excursions. ${ }^{6-8}$

The physiology of GLP-1 and its possible promising role as a pharmacological tool for treating type 2 diabetes was first described in the late 1990s. In contrast to the classical insulinotropic agents (sulfonylureas and glynides), the insulinotropic action of GLP-1 is strictly glucose dependent. GLP-1 stimulates insulin secretion only during hyperglycemia. This effect provides the possibility of glucose normalization without the risk of hypoglycemia. In patients with type 2 diabetes with hyperglycemia, exogenous parenteral GLP-1 application stimulates insulin secretion and normalizes both fasting and postprandial blood glucose. GLP-1 is also able to restore the defective first phase of insulin secretion in type 2 diabetes. $^{2}$
Besides these antihyperglycemic effects, GLP-1 also possesses additional noninsulinotropic physiological actions that are attractive for type 2 diabetes treatment: GLP-1 suppresses glucagon secretion from the alpha-cells also in a glucose dependent manner. Under hyperglycemic conditions, glucagon secretion is inhibited, while under hypoglycemia, glucagon secretion is even increased. The latter effect also contributes to the low hypoglycemia risk with GLP-1 based therapies. ${ }^{2,9}$

Furthermore, GLP-1 slows gastric emptying and gastrointestinal motility. It also acts as a mediator of satiety in the hypothalamus, where it is an important neurotransmitter. ${ }^{2,5}$ These two actions are responsible for the observation that in healthy subjects and type 2 diabetes patients GLP-1 infusions lead to decreased caloric intake and consecutively weight loss..$^{10,11}$

GLP-1 has beneficial effects on beta-cell function and mass by stimulating beta-cell formation from precursor cells and inhibiting beta-cell apoptosis., ${ }^{2,11,12}$

Dipeptidyl peptidase-4 (DPP-4) is the enzyme that is responsible for the degradation of GLP-1 resulting in its short biological half-life of only 1-2 minutes. Due to the extremely short biological half-life, treatment with native GLP-1 is not feasible. In order to use GLP-1 effects as therapeutic principle, long-acting GLP-1 receptor agonists have been developed as an injectable therapy. The other alternative to utilize GLP-1 action is the inhibition of the degrading enzyme DPP-4 by orally active DPP-IV inhibitors. ${ }^{2,13}$

DPP-4 is a ubiquitous enzyme and is found in the endothelium of various organs as well as measurable circulating enzymatic activity in plasma in soluble form. Besides GLP-1 many other peptides are substrates of DPP-4, but the affinity towards GLP-1 is predominant. DPP-4 cleaves and inactivates GLP-1 within a few minutes. ${ }^{14}$ DPP-4 is also expressed on the cell membrane of activated T-lymphocytes where it was first described as CD26 receptor. ${ }^{14}$ The enzymatic functions and the active center of DPP-4 are, however, localized in a distant part of the molecule in respect to the CD26 receptor function. An influence of DPP-4 inhibitors on immunological CD26 mediated functions is therefore not expected and unlikely. The broad clinical use of DPP-4 inhibitors has so far not revealed serious side effects or adverse events on immunological regulatory mechanisms. ${ }^{2}$

DPP-4 inhibition promotes an attractive therapeutic principle by increasing plasma concentrations of endogenous GLP-1. While GLP-1 receptor agonists are injectable compounds, DPP-4 inhibitors are orally active. ${ }^{2}$ DPP-4 belongs to the enzyme family of endopeptidases. DPP-4 
inhibitors must therefore have a high selectivity to inhibit only DPP-4 and not other DPPs. The DPP-4 inhibitors sitagliptin and vildagliptin have already been approved in many countries and have been shown to be efficacious and safe due to their DPP-4 selectivity. ${ }^{15,16}$ Saxagliptin, a novel DPP-4 inhibitor, was developed by AstraZeneca and Brystol-Myers Squibb and has just been approved (trade name Onglyza ${ }^{\circledR}$ ). Further DPP-4 inhibitors such as alogliptin, dutogliptin and linagliptin are in development. ${ }^{17,18}$

\section{Development, synthesis and preclinical pharmacology of saxagliptin}

In the development of DPP-4 inhibitors, a long duration of action was a desirable feature. Compounds with a vinyl substitution at the $\beta$-position of $\alpha$-cycloalkyl-substituted glycines and their oxygenated metabolites did not lead to a loss of potency, but to a desired increase in duration of action. ${ }^{19,20}$ Consecutive exploration of molecules with an hydroxylated adamantyl group led to saxagliptin, that is characterized by a high in vitro and in vivo potency, good oral bioavailability $(\mathrm{F}=75 \%)$, good duration of action ( $\mathrm{t} 1 / 2=2.1$ hours) and no CYP3A4 inhibition. ${ }^{20-23}$ Saxagliptin interacts with DPP-4 at the Ser630 residue in the active center of DPP-4. The formation of the covalent complex of saxagliptin and DPP-4 is reversible, with a dissociation constant $\left(\mathrm{k}_{\text {off }}\right)$ of $5.5 \pm$ $0.4 \times 10^{-5} \mathrm{~s}^{-1}$ and an equilibrium constant $\mathrm{K}_{i} *\left(\right.$ as $\left.\mathrm{k}_{\text {off }} / \mathrm{k}_{\text {on }}\right)$ for the formation of the covalent intermediate of $0.35 \mathrm{nM}$. This value is similar to the value obtained from steady-state inhibition studies of $0.6 \mathrm{nM} .^{21,24,25}$

Saxagliptin has a very high selectivity for DPP-4 and its in vitro potency shows a 400- and 75-fold higher potency versus DPP-4 than for DPP-8 or DPP-9, respectively. It also demonstrates a more than 4000-fold greater potency for DPP-4 in comparison to a number of other proteases. Saxagliptin possesses a dissociation constant for inhibitor binding $\left(\mathrm{K}_{i}\right)$ of $1.3 \pm 0.3 \mathrm{nM}$ for inhibiting DPP-4, making it 10- and 14fold more potent than vildagliptin $(13 \pm 3 \mathrm{nM})$ and sitagliptin $(18 \pm 2 \mathrm{nM})$, respectively. ${ }^{26}$

In vivo saxagliptin has an $\mathrm{IC}_{50}$ value for DPP-4 inhibition of $30 \mathrm{nM}$ and $\mathrm{ED}_{50}$ values at 0.5 and 6 hours were attained with saxagliptin at 0.1 and $0.5 \mu \mathrm{mol} / \mathrm{kg}$, respectively, demonstrating a good activity over time and long duration. A significant rise of endogenous GLP-1 was observed after an oral glucose challenge in healthy rats with a saxagliptin dose of $3 \mu \mathrm{mol} / \mathrm{kg}$ and no inhibition of T-cell activity was detected. ${ }^{20,21}$
The in vivo DPP-4 inhibitory activity in Sprague-Dawley rats was $87 \%$. The $\mathrm{K}_{i}$ value was $0.6 \pm 0.06 \mathrm{nM}$, the $\mathrm{ED}_{50}$ values at $0.5,2,4$ and 6 hours post-administration were $0.12 \pm 0.04,0.2 \pm 0.07,0.3 \pm 0.10$ and $0.5 \pm 0.15 \mu \mathrm{mol} /$ $\mathrm{kg}$, respectively. In a diabetes, insulin-resistant rat model, saxagliptin ( 0.3 to $3 \mu \mathrm{mol} / \mathrm{kg} \mathrm{po}$ ) improved glucose clearance by $28 \%-61 \%$ relative to controls at 2 hours after glucose challenge. Saxagliptin was also effective at raising insulin levels and increasing glucose clearance in ob/ob mice at 1 , 3 or $10 \mu \mathrm{mol} / \mathrm{kg}$ po. ${ }^{24}$

In man, the $\mathrm{IC}_{50}$ for DPP-4 inhibition by saxagliptin is 30 $\mathrm{nM}$, the $\mathrm{ED}_{50} 0.5$ and 6 hours after a single dose are 0.1 and $0.5 \mu \mathrm{mol} / \mathrm{kg}$, respectively. Therefore, saxagliptin has sufficient activity over time for once daily dosing. Saxagliptin is metabolized in humans forming an active metabolite. The active metabolite BMS-510849 is 2-fold less potent than saxagliptin. The endogenous GLP-1 concentrations rise 1.5- to 3.0-fold after oral administration of saxagliptin. ${ }^{21,27}$ Pharmacokinetic and pharmacodynamic properties of saxagliptin were investigated in healthy subjects at doses up to $400 \mathrm{mg}$ daily and in type 2 diabetes patients in doses from $2.5 \mathrm{mg}$ to $50 \mathrm{mg}$ od. The maximally DPP-4 inhibiting effect of saxagliptin was observed at a single dose of $150 \mathrm{mg}$. Percentages of DPP-4 inhibition 24 hours post-dose for $2.5 \mathrm{mg}$ and $400 \mathrm{mg}$ saxagliptin were $50 \%$ and $79 \%$ of the predose activity, respectively. Doses of $400 \mathrm{mg}$ od saxagliptin for 2 weeks were safe and well tolerated. ${ }^{21,28}$ So far, no specific drug-drug interactions were detected for saxagliptin and other commonly used medications. ${ }^{29-32}$

\section{Clinical studies with saxagliptin}

Phase 1 studies showed a dose dependent DPP-4 inhibition in a dose range from 2.5 to $100 \mathrm{mg}$ saxagliptin given once daily. In a large phase 2 study in drug-naive patients $(n=350)$ with inadequately controlled type 2 diabetes saxagliptin was given in doses of $2.5,5,10,20$ or $40 \mathrm{mg} /$ day po for 12 weeks or $100 \mathrm{mg} /$ day po for 6 weeks. The baseline $\mathrm{HbA}_{\mathrm{lc}}$ ranged from $6.8 \%-9.7 \%$. In the placebo group, $20 \%$ of patients achieved $\mathrm{HbA}_{1 \mathrm{c}}$ levels of $<7.0 \%$, compared with $50 \%, 47 \%, 41 \%, 50 \%$, $53 \%$ and $66 \%$ of patients in the saxagliptin groups, respectively. Fasting plasma glucose and post-challenge glucose after a liquid meal were also dose dependently and significantly improved by saxagliptin. ${ }^{21,28,33} \mathrm{~A}$ subsequent phase 2B/phase 3 study investigated saxagliptin as add-on to metformin. Patients on a stable dose of metformin (1500-2550 mg/day) and a baseline $\mathrm{HbA}_{1 \mathrm{c}} 7.0 \%-10.0 \%$ were enrolled. Saxagliptin was tested against placebo at doses of $2.5,5$ or $10 \mathrm{mg}$ od administered as add-on to metformin. A total of 743 patients participated 
in this 24-week trial. Saxagliptin led to a decrease in $\mathrm{HbA}_{1 \mathrm{c}}$ compared to placebo of $-0.73 \%,-0.83 \%$ and $-0.71 \%$ from a baseline of $8.0 \pm 0.9 \%$ for the $2.5,5$ or $10 \mathrm{mg}$ dose after 24 weeks, respectively $(P<0.0001)$. The fasting plasma glucose also significantly decreased by $-16,-24$ and $-21 \mathrm{mg} / \mathrm{dL}$ from a baseline of $176 \pm 46 \mathrm{mg} / \mathrm{dL}(P<0.0001)$. In oral glucose tolerance tests, saxagliptin significantly improved glycemic excursions and reduced the glucose and glucagon AUCs while increasing the AUCs for insulin and C-peptide. The therapy with saxagliptin was well tolerated and the incidence of hypoglycemic events was on placebo level. The treatment with saxagliptin was weight neutral (body weight change of $-1.5,-0.9,-0.5$, and $-1.0 \mathrm{~kg}$ for $2.5,5$, and $10 \mathrm{mg}$ saxagliptin and placebo, respectively). ${ }^{34}$

The study program leading to the approval of saxagliptin was extensive. Figure 1 shows the phase 3 program of the clinical studies and the number of patient's involved. ${ }^{34-38}$

A dose-range study in drug naïve type 2 diabetic patients with an $\mathrm{HbA}_{1 \mathrm{c}}$ of $6.8 \%-9.7 \%$ (mean $7.9 \%$ ) at baseline were treated with saxagliptin in a dose range from $2.5 \mathrm{mg}$ to $40 \mathrm{mg}$ once daily. The treatment with saxagliptin led to a dose-dependent placebo subtracted reduction in $\mathrm{HbA}_{1 \mathrm{c}}$ by $0.45 \%-0.63 \%$. The fasting- and postprandial plasma glucose concentrations were also lowered dosedependently by saxagliptin. The drug did not cause hypoglycemia, was well tolerated and was weight neutral as in other studies. $^{36,39}$

An initial combination therapy with saxagliptin plus metformin versus saxagliptin or metformin monotherapy lasting 24 weeks demonstrated that saxagliptin $5 \mathrm{mg}$ plus metformin and saxagliptin $10 \mathrm{mg}$ plus metformin demonstrated statistically significant decreases in glycemic parameters. The aim of this study was to evaluate the efficacy and safety of an initial combination treatment with saxagliptin plus metformin and compare it to a saxagliptin- or metformin monotherapy in treatment-naïve patients with type 2 diabetes and inadequate glycemic control. A total of 1306 patients were enrolled in this 24-week study. At the end of the trial, the proportion of patients reaching an $\mathrm{HbA}_{1 \mathrm{c}}$ goal $<7 \%$ was $60.3 \%$ and $59.7 \%$ for saxagliptin $5 \mathrm{mg}$ plus metformin and saxagliptin $10 \mathrm{mg}$ plus metformin, respectively (all $P<0.0001$ vs monotherapy). The incidence of adverse events was comparable in all groups and the overall rate of hypoglycemic episodes was very low on placebo level. ${ }^{38}$

As add-on therapy in patients treated with a sulfonylurea, saxagliptin, when added to a submaximal dose of glyburide, improved glycemic parameters significantly and was superior to up titrating the sulfonylurea. In this study, a total of
768 patients were randomized to receive $2.5 \mathrm{mg}$ or $5 \mathrm{mg}$ in combination with glyburide $7.5 \mathrm{mg}$ or glyburide $10 \mathrm{mg}$ as monotherapy for 24 weeks. At the end of the study, $92 \%$ of patients on glyburide monotherapy were up titrated to a total glyburide dose of $15 \mathrm{mg} /$ day, corresponding to the maximal dose allowed according to the study protocol. Saxagliptin at the doses of $2.5 \mathrm{mg}$ and $5 \mathrm{mg}$ od provided statistically significant adjusted mean decreases of $\mathrm{HbA}_{1 \mathrm{c}}$ from baseline to week 24 vs up titrated glyburide of $-0.54 \%,-0.64 \%$ vs $+0.08 \%$, respectively (both $P<0.0001$ ). Other glycemic parameters (fasting plasma glucose, postprandial glucose, proportion of patients reaching an $\mathrm{HbA}_{1 \mathrm{c}}$ goal $<7 \%$ ) were significantly better in the groups receiving saxagliptin. Reported hypoglycemic events were not statistically significantly different for saxagliptin $2.5 \mathrm{mg}(13.3 \%)$ and $5 \mathrm{mg}(14.6 \%)$ vs up titrated glyburide (10.1\%) and the incidence of adverse events was similar in all groups. ${ }^{37}$

The efficacy and safety of saxagliptin were also investigated in a study using saxagliptin as an add on to a pre-existing therapy with glitazones in type 2 diabetic patients with a baseline $\mathrm{HbA}_{1 \mathrm{c}}$ of $7.0 \%-10.5 \%$. A total of 565 patients receiving stable glitazone monotherapy (pioglitazone $30 \mathrm{mg}$ or $45 \mathrm{mg}$ or rosiglitazone $4 \mathrm{mg}$ or $8 \mathrm{mg}$ od) were treated with either 2.5 $\mathrm{mg}$ or $5 \mathrm{mg}$ saxagliptin or placebo as add-on for 24 weeks. Both doses of saxagliptin ( $2.5 \mathrm{mg}$ and $5 \mathrm{mg}$ ) as add-on to a glitazone led to statistically significant adjusted mean decreases in $\mathrm{HbA}_{1 \mathrm{c}}$ vs placebo $(-0.66 \%$ and $-0.94 \%$ for saxagliptin $2.5 \mathrm{mg}$ and $5 \mathrm{mg}$ vs $-0.30 \%$ for placebo). Fasting plasma glucose, postprandial glucose and the proportion of patients reaching an $\mathrm{HbA}_{1 \mathrm{c}}$ goal $<7 \%$ were significantly improved in the saxagliptin treated patients. Saxagliptin was generally well tolerated; adverse event occurrence and reported hypoglycemic events were similar across all groups. ${ }^{40}$

A study assessing the efficacy of $5 \mathrm{mg}$ saxagliptin daily used different insulin secretion parameters after 12 weeks as efficacy measures in 156 patients not well controlled with diet and exercise $\left(\mathrm{HbA}_{1 \mathrm{c}} \text { between } 6.0 \% \text { and } 8.0 \%\right)^{21,28,33}$

A study in patients with impaired renal function (creatinine clearance $<50 \mathrm{~mL} / \mathrm{min}$ ) is still ongoing and investigating the efficacy and safety of $2.5 \mathrm{mg}$ saxagliptin given od. ${ }^{21,28,33}$

A study in 18 patients with hepatic impairment (ChildPugh Score A-C) compared the pharmacokinetics of $10 \mathrm{mg}$ saxagliptin to a healthy control group. A higher elevation of AUC values after saxagliptin (10\%-77\% higher) was observed in the patients with hepatic impairment. Correspondingly, the AUC values for the metabolite were 7\%-33\% lower, depending on the severity of hepatic impairment. These results indicate a reduced capacity to metabolize the drug with increasing 


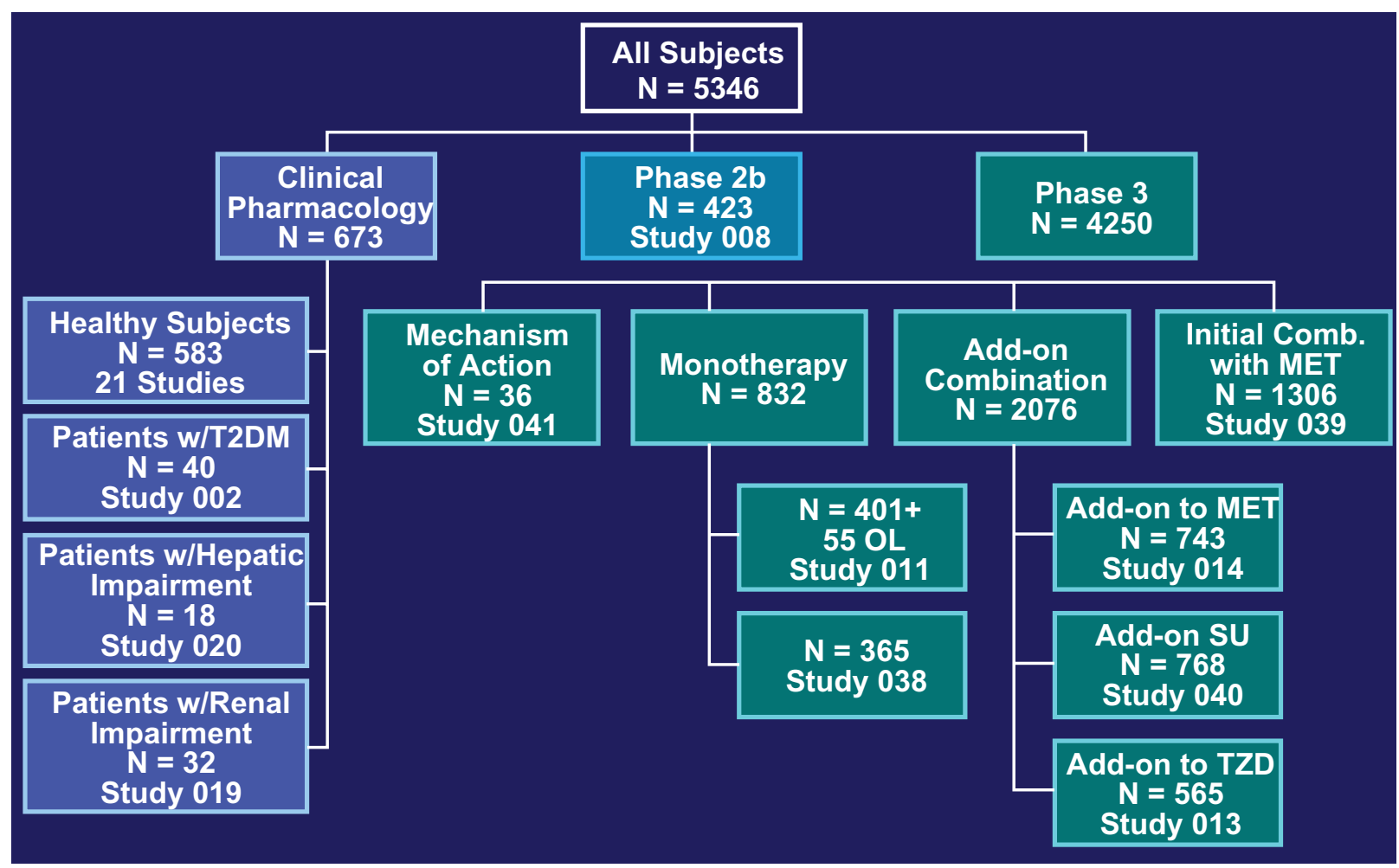

Figure I Overview of the clinical study program of saxagliptin leading to approval. ${ }^{45}$

Abbreviations: MET, metformin; OL, open-label; SU, sulfonylurea;T2DM, type 2 diabetes mellitus;TZD, thiazolidinedione.

hepatic dysfunction. Saxagliptin, however, was well tolerated in subjects with mild, moderate or severe hepatic impairment. ${ }^{21,41}$

\section{Adverse effects and contraindications}

In clinical studies, DPP-4 inhibitors are generally well tolerated and fullness, nausea, or other gastrointestinal symptoms related to retarded gastric emptying are rare. Nasopharyngitis and urinary tract infections were reported in a small number of patients treated with DPP-4 inhibitors. DPP-4, also known as CD26, is found as a membrane protein expressed in many different tissues, including lymphocytes, and in a circulating soluble form; DPP-4 inhibitors also prolong the action of a number of growth factors, neuropeptides, cytokines, chemokines, and various hormones other than
GLP-1 and gastric inhibitory polypeptide (GIP). Potential side effects therefore include neurogenic inflammation and allergic reactions, which have not been reported in a significant number so far.

Saxagliptin in doses up to $100 \mathrm{mg}$ od was tested in type 2 diabetes patients and doses up to $400 \mathrm{mg}$ were tested in healthy subjects. These doses did not cause specific adverse reactions and tolerability was good. ${ }^{21,28,33}$ Besides that, data from longer studies investigating the adverse events and safety of saxagliptin are available. In the clinical phase 3 program, saxagliptin at doses from $2.5 \mathrm{mg}$ to $10 \mathrm{mg}$ od were well tolerated without a significant rise in specific adverse reactions compared to placebo. The hypoglycemia incidence was also not increased compared to placebo. ${ }^{21,28,33-40}$ A study in formerly drug-naïve type 2 diabetes patients using doses of up to $40 \mathrm{mg}$ saxagliptin once daily did not reveal

Table I Monotherapy studies with saxagliptin

\begin{tabular}{|c|c|c|c|c|c|c|c|c|c|}
\hline & \multicolumn{3}{|c|}{ Saxagliptin (mg) } & \multirow[t]{2}{*}{ Placebo } & \multicolumn{4}{|c|}{ Saxagliptin (mg) } & \multirow[t]{2}{*}{ Placebo } \\
\hline & & & & & QAM & QAM & QAM & QPM & \\
\hline Dose & 2.5 & 5 & 10 & - & 2.5 & 5 & $2.5 / 5$ & 5 & - \\
\hline $\mathrm{n}=$ & 100 & 103 & 95 & 92 & 67 & 69 & 69 & 70 & 68 \\
\hline Basal mean $\mathrm{HbA}_{\mathrm{IC}}(\%)$ & 7.91 & 7.98 & 7.85 & 7.88 & 8.04 & 7.93 & 8.02 & 7.88 & 7.79 \\
\hline
\end{tabular}

Notes: For $\mathrm{HbA}_{\mathrm{IC}}$ changes, see Figure 2.

Abbreviations: QAM, every morning; QPM, every afternoon. 
Table 2 Add on combination therapy studies with saxagliptin

\begin{tabular}{|c|c|c|c|c|c|c|c|c|c|c|}
\hline \multirow[b]{2}{*}{ Dose } & \multicolumn{2}{|c|}{ SAXA + MET } & \multicolumn{2}{|c|}{ PBO + MET } & \multicolumn{2}{|c|}{ SAXA + TZD } & \multirow{2}{*}{$\begin{array}{l}\text { PBO + TZD } \\
-\end{array}$} & \multicolumn{2}{|c|}{ SAXA + GLY } & \multirow{2}{*}{$\begin{array}{l}\text { PBO + GLY } \\
-\end{array}$} \\
\hline & 2.5 & 5 & 10 & - & 2.5 & 5 & & 2.5 & 5 & \\
\hline $\mathrm{n}=$ & 186 & 186 & 180 & 175 & 192 & 183 & 180 & 246 & 250 & 264 \\
\hline Basal mean $\mathrm{HbA}_{\mathrm{lc}}(\%)$ & 8.08 & 8.07 & 7.98 & 8.06 & 8.25 & 8.35 & 8.19 & 8.36 & 8.48 & 8.44 \\
\hline
\end{tabular}

Notes: For $\mathrm{HbA}_{\mathrm{IC}}$ changes, see Figure 2

Abbreviation: SAXA, saxagliptin; MET, metformin;TZD, thiazolidinedione; PBO, placebo; GLY, glyburide.

a higher incidence of specific adverse events compared to the placebo group. ${ }^{39}$ Possible drug-drug interactions with saxagliptin were also examined extensively and did not give a signal for drug-drug interactions between saxagliptin and common medications. ${ }^{21,29-32}$ In patients with renal or hepatic impairment, additional data have to be obtained to be able to evaluate the safety and efficacy of saxagliptin in these patient groups. One study in patients with renal impairment is still ongoing. In hepatic organ dysfunction, dose reductions to lower doses seem to be feasible without additional side effects. Saxagliptin was well tolerated in a small study such patients receiving a single saxagliptin dose. ${ }^{41}$

\section{Discussion and perspectives}

DPP-4 inhibitors have been introduced into type 2 diabetes therapy in 2006 with sitagliptin as first substance, ${ }^{16}$ followed by vildagliptin ${ }^{15}$ and now saxagliptin in 2009. The DPP-4 nhibitors are the first substances having a glucose-dependent dual action on alpha- and beta-cell function stimulating insulin secretion and suppressing glucagon secretion under hyperglycemic conditions. This dual action leads to an improved time course of islet hormone secretion after a meal and in hyperglycemia. The glucose-dependent action results in a hypoglycemia risk that is comparable to placebo treatment. On the other hand, hormonal counter-regulation in hypoglycemia is not impaired, but actually improved. ${ }^{42}$ Animal studies and in vitro data from isolated human islets suggest that DPP-4 inhibitors increase beta-cell function and mass. These findings may support the hypothesis that DPP-4 inhibitors as well as a therapy with GLP-1 analogs have a beneficial effect on disease progression of type 2 diabetes. ${ }^{17,18}$ Clinical studies with saxagliptin have demonstrated very satisfactory data on the improvement of glycemic parameters together with a good safety profile and good tolerability over a time range up to 24 weeks in clinical studies in a large cohort of patients. ${ }^{21,28,33-39,41,43}$ (see Tables 1 and 2, Figure 2). In comparison to other sitagliptin and vildagliptin, saxagliptin shows a similar efficacy and safety profile in monotherapy as well as in the initial combination with metformin or as add-on to metformin or a glitazone..$^{21,28,33-40}$ Additional studies also showed that there is no serious drug-drug interaction with other common medications often taken by type 2 diabetic patients, eg, antacids, anticoagulants and digitoxin. ${ }^{29-32} \mathrm{~A}$ small study investigating the pharmacokinetics of saxagliptin in patients with hepatic impairment demonstrated a slower metabolization of saxagliptin, but no severe side effects. ${ }^{41}$

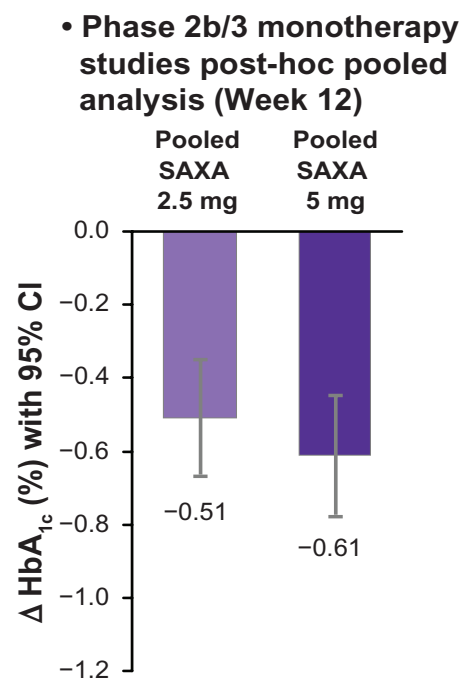

\section{- Phase 3 add-on combination studies short-term period (Week 24)}

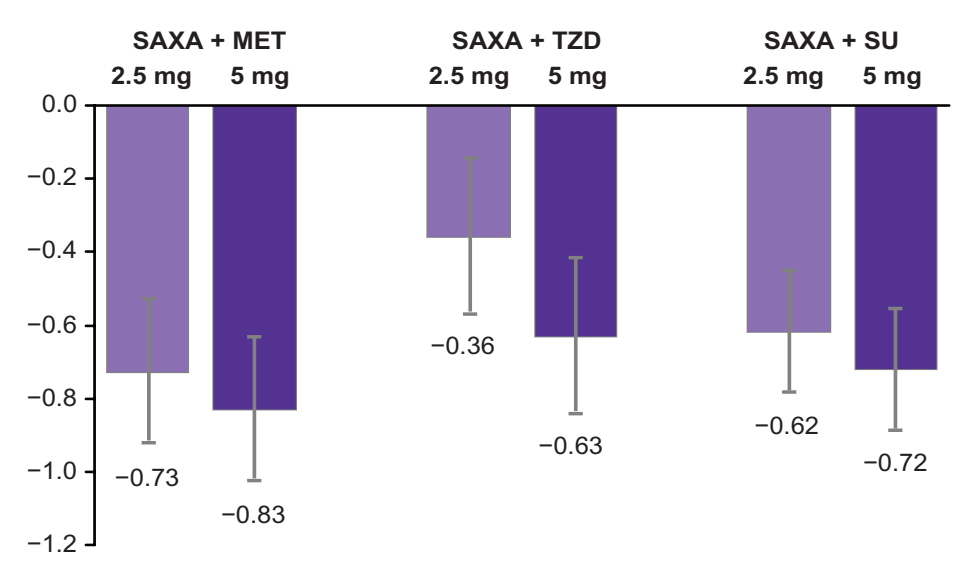

Figure 2 Pooled data of the $\mathrm{HbA}_{1 \mathrm{c}}$ reductions observed in the clinical studies with saxagliptin (SAXA):34-36,38-40,45 The left hand side of the figure shows the pooled monotherapy results, the right side shows the $\mathrm{HbA}_{\mathrm{lc}}$ reductions in various combinations with either metformin (MET), thiazolidinedione (TZD) or sulfonylurea (SU). In each study, the results for doses with $2.5 \mathrm{mg}$ saxagliptin od (light bars) or $5 \mathrm{mg}$ saxagliptin od (dark bars) are shown. 


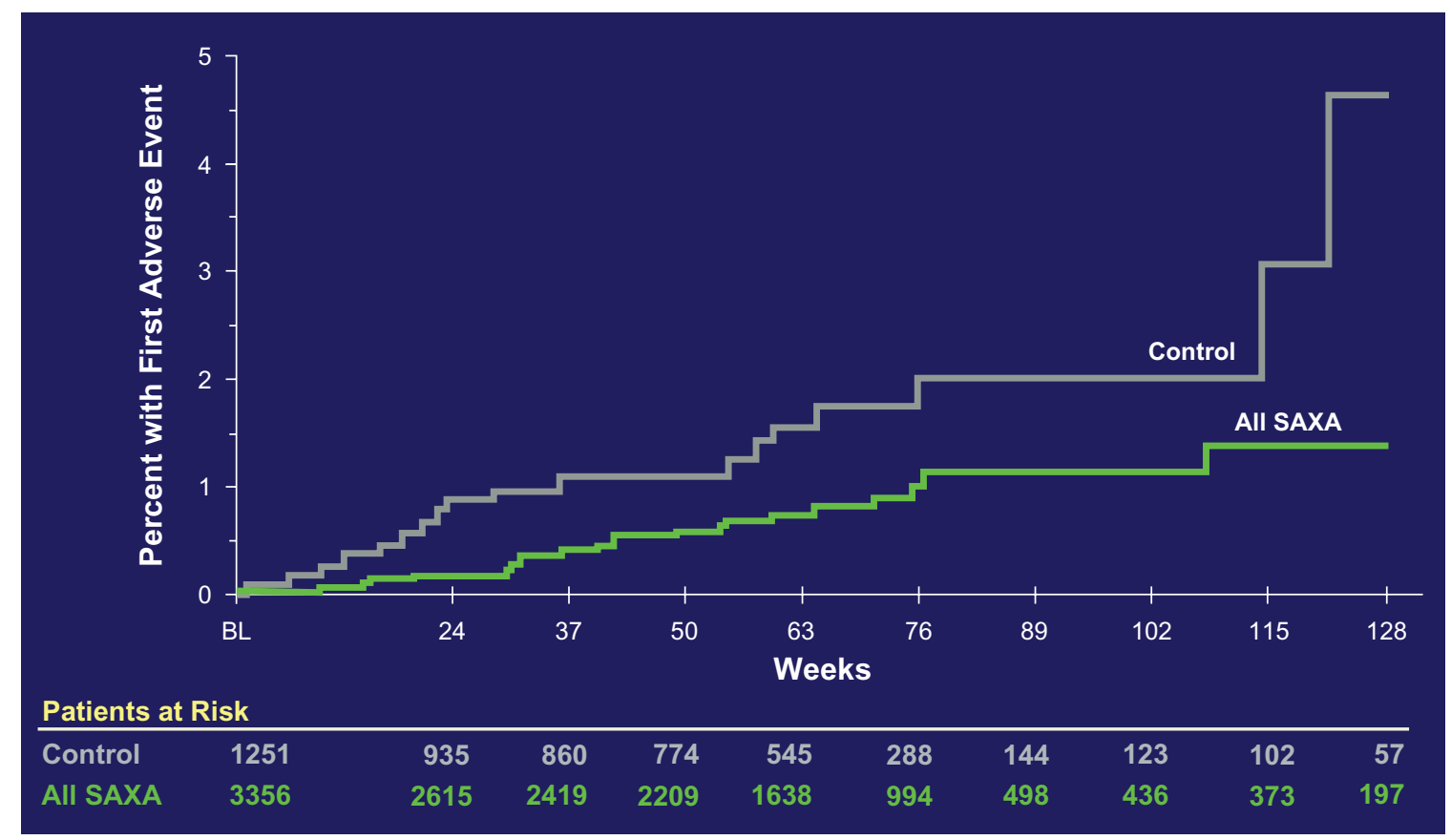

Figure 3 Cardiovascular safety data of saxagliptin (SAXA). The cumulative incidence of major adverse cardiovascular events (MACE) is shown. ${ }^{43}$ MACE is defined as a combined "major adverse cardiovascular event" consisting of the items cardiovascular death, nonfatal myocardial infarction, and nonfatal stroke. On the ordinate of the figure, the percentage of patients having had a first incident of the MACE-defining adverse events are depicted.

A larger study on the efficacy and safety of saxagliptin in type 2 diabetes patients with renal impairment is still ongoing. ${ }^{21}$

In a head-to-head study comparing sitagliptin as the first in class DPP-4 inhibitor with saxagliptin, saxagliptin was noninferior to sitagliptin (press release by AstraZeneca and Bristol-Myers Squibb, Oct 5th, 2009). A meta-analysis of the existing phase 2 and phase 3 studies showed favorable cardiovascular outcomes in the saxagliptin-treated patients. ${ }^{43}$ (see Figure 3). The development of saxagliptin as well as the other DPP-4 inhibitors emphasizes the advantages of DPP-4 inhibitors over classical insulin secretagogues (sulfonylureas and meglitinides) concerning their glucose-dependent action without intrinsic hypoglycemia risk and weight neutrality. ${ }^{44}$

Saxagliptin has the advantage of having a very high selectivity towards DPP-4 and in comparison to sitagliptin and vildaglitpin it has a significantly higher potency to inhibit DPP-4 in vitro. These effects result in the low dose of the drug that has to be administered in type 2 diabetes therapy. Whether these in vitro data and the advantage of the low drug dose translate into a clinically meaningful difference to distinguish saxagliptin from the other DPP-4 inhibitors is not known yet. The head-to-head study comparing sitagliptin and saxagliptin has shown noninferiority for saxagliptin. The cardiovascular event rates from the combined study program carried out for the approval of saxagliptin are very favorable and have so far not been shown for the other DPP-4 inhibitors.
In the long run, however, long-term efficacy and safety data are necessary to show the potential advantages of saxagliptin in comparison to other DPP-4 inhibitors.

\section{Disclosures}

The author is a member on advisory boards for AstraZeneca, Bristol-Myers Squibb, Boehringer Ingelheim, Eli Lilly, Novartis, Novo Nordisk, Merck, Roche, and Takeda and has also received honoraria from these companies for giving lectures.

\section{References}

1. IDF: IDF Diabetes Atlas. http://www.diabetesatlas.org/, 2009.

2. Drucker DJ, Nauck MA. The incretin system: glucagon-like peptide-1 receptor agonists and dipeptidyl peptidase- 4 inhibitors in type 2 diabetes. Lancet. 2006;368:1696-1705.

3. Prentki M, Nolan CJ. Islet beta cell failure in type 2 diabetes. $J$ Clin Invest. 2006;116:1802-1812.

4. Mitrakou A, Ryan C, Veneman T, et al. Hierarchy of glycemic thresholds for counter regulatory hormone secretion, symptoms, and cerebral dysfunction. Am J Physiol. 1991;260:E67-E74

5. Gallwitz B. Therapies for the treatment of type 2 diabetes mellitus based on incretin action. Minerva Endocrinol. 2006;31:133-147.

6. Creutzfeldt W. The incretin concept today. Diabetologia. 1979;16:75-85.

7. Nauck M, Stockmann F, Ebert R, Creutzfeldt W. Reduced incretin effect in type 2 (non-insulin-dependent) diabetes. Diabetologia. 1986;29:46-52.

8. Nauck MA, Heimesaat MM, Orskov C, Holst JJ, Ebert R, Creutzfeldt W. Preserved incretin activity of glucagon-like peptide 1 [7-36 amide] but not of synthetic human gastric inhibitory polypeptide in patients with type-2 diabetes mellitus. J Clin Invest. 1993;91:301-307.

9. Nauck MA, Kleine N, Orskov C, Holst JJ, Willms B, Creutzfeldt W. Normalization of fasting hyperglycemia by exogenous glucagon-like peptide 1 (7-36 amide) in type 2 (non-insulin-dependent) diabetic patients. Diabetologia. 1993;36:741-744. 
10. Gutzwiller JP, Drewe J, Goke B, et al. Glucagon-like peptide-1 promotes satiety and reduces food intake in patients with diabetes mellitus type 2 . Am J Physiol. 1999;276:R1541-R1544.

11. Zander M, Madsbad S, Madsen JL, Holst JJ. Effect of 6-week course of glucagon-like peptide 1 on glycemic control, insulin sensitivity, and beta-cell function in type 2 diabetes: a parallel-group study. Lancet. 2002;359:824-830.

12. Drucker DJ. The biology of incretin hormones. Cell Metab. 2006;3: 153-165.

13. Deacon CF, Nauck MA, Toft-Nielsen M, Pridal L, Willms B, Holst JJ. Both subcutaneously and intravenously administered glucagon-like peptide I are rapidly degraded from the $\mathrm{NH} 2$-terminus in type II diabetic patients and in healthy subjects. Diabetes. 1995;44:1126-1131.

14. Mentlein R. Dipeptidyl-peptidase IV (CD26) - role in the inactivation of regulatory peptides. Regul Pept. 1999;85:9-24.

15. Garber AJ, Sharma MD. Update: vildagliptin for the treatment of type 2 diabetes. Expert Opin Investig Drugs. 2008;17:105-113.

16. Karasik A, Aschner P, Katzeff H, Davies MJ, Stein PP. Sitagliptin, a DPP-4 inhibitor for the treatment of patients with type 2 diabetes: a review of recent clinical trials. Curr Med Res Opin. 2008;24:489-496.

17. Thornberry NA, Gallwitz B. Mechanism of action of inhibitors of dipeptidyl-peptidase-4 (DPP-4). Best Pract Res Clin Endocrinol Metab. 2009;23:479-486.

18. Ahren B. Emerging dipeptidyl peptidase-4 inhibitors for the treatment of diabetes. Expert Opin Emerg Drugs. 2008;13:593-607.

19. Magnin DR, Robl JA, Sulsky RB, et al. Synthesis of novel potent dipeptidyl peptidase IV inhibitors with enhanced chemical stability: interplay between the N-terminal amino acid alkyl side chain and the cyclopropyl group of alpha-aminoacyl-1-cis-4,5-methanoprolinenitrilebased inhibitors. J Med Chem. 2004;47:2587-2598.

20. Augeri DJ, Robl JA, Betebenner DA, et al. Discovery and preclinical profile of saxagliptin (BMS-477118): a highly potent, long-acting, orally active dipeptidyl peptidase IV inhibitor for the treatment of type 2 diabetes. $J$ Med Chem. 2005;48:5025-5037.

21. Gallwitz B. Saxagliptin, a dipeptidyl peptidase IV inhibitor for the treatment of type 2 diabetes. IDrugs. 2008;11:906-917.

22. Cao K, Bonacorsi SJ Jr, Balasubramanian B, et al. Carbon-14 labelling of saxagliptin (BMS-477118). J Labelled Compd Radiopharm. 2007;50:1224-1229.

23. Sharma PN, Galvin GM, Boettger SD, et al. US-20060035954: Ammonolysis process for the preparation of intermediates for DPP IV inhibitors. U.S. Patent. 20060035954, 2006.

24. Kim YB, Kopcho LM, Kirby MS, et al. Mechanism of Gly-Pro-pNA cleavage catalyzed by dipeptidyl peptidase-IV and its inhibition by saxagliptin (BMS-477118). Arch Biochem Biophys. 2006;445:9-18.

25. Metzler WJ, Yanchunas J, Weigelt C, et al. Involvement of DPP-IV catalytic residues in enzyme-saxagliptin complex formation. Protein Sci. 2008;17:240-250.

26. Wang AY, Dorso C, Kopcho LM, Marcinkeviciene J, Kirby MS. Implications of the prolonged dissociation rate of saxagliptin, a highly potent and selective DPP4 inhibitor, on plasma DPP measurements. Diabetes. 2008;57:A576-A577.

27. Fura A, Khanna A, Vyas V, et al. Pharmacokinetics of the dipeptidyl peptidase 4 inhibitor saxagliptin in rats, dogs, and monkeys and clinical projections. Drug Metab Dispos. 2009;37:1164-1171.
28. Deacon CF, Holst JJ. Saxagliptin: a new dipeptidyl peptidase-4 inhibitor for the treatment of type 2 diabetes. Adv Ther. 2009;26:488-499.

29. Girgis S, Patel CG, Li L, et al. Effect of diltiazem on the pharmacokinetics of saxagliptin in healthy subjects. J Clin Pharmacol. 2007;47:119.

30. Boulton DW, Brenner E, Royzman K, Li L. Effect of ketoconazole on the pharmacokinetics of saxagliptin in healthy subjects. J Clin Pharmacol. 2007;47:1203.

31. Boulton DW, Adams D, Li L, et al. Magnesium and aluminum hydroxides plus simethicone, famotidine, or omeprazole do not meaningfully affect the pharmacokinetics of saxagliptin in healthy subjects. Clin Pharmacol Therapeutics. 2008;83 Suppl 1:S92-S93.

32. Boulton DW, Li L, Patel CG, et al. No pharmacokinetic interaction between saxagliptin and digoxin in healthy subjects. Clin Pharmacol Therapeutics. 2008;83 Suppl 1:S93

33. Tahrani AA, Piya MK, Barnett AH: Saxagliptin: a New DPP-4 inhibitor for the treatment of type 2 diabetes mellitus. Adv Ther. 2009;26:736.

34. DeFronzo RA, Hissa MN, Garber AJ, et al. The efficacy and safety of saxagliptin when added to metformin therapy in patients with inadequately controlled type 2 diabetes with metformin alone. Diabetes Care. 2009;32:1649-1655.

35. Dhillon S, Weber J. Saxagliptin. Drugs. 2009;69:2103-2114.

36. Rosenstock J, Aguilar-Salinas C, Klein E, Nepal S, List J, Chen R. Effect of saxagliptin monotherapy in treatment-naive patients with type 2 diabetes. Curr Med Res Opin. 2009;25:2401-2411.

37. Chacra AR, Tan GH, Apanovitch A, Ravichandran S, List J, Chen R. Saxagliptin added to a submaximal dose of sulphonylurea improves glycemic control compared with up titration of sulphonylurea in patients with type 2 diabetes: a randomised controlled trial. Int J Clin Pract. 2009;63:1395-1406.

38. Jadzinsky M, Pfutzner A, Paz-Pacheco E, Xu Z, Allen E, Chen R. Saxagliptin given in combination with metformin as initial therapy improves glycemic control in patients with type 2 diabetes compared with either monotherapy: a randomized controlled trial. Diabetes Obes Metab. 2009;11:611-622.

39. Rosenstock J, Sankoh S, List JF. Glucose-lowering activity of the dipeptidyl peptidase-4 inhibitor saxagliptin in drug-naive patients with type 2 diabetes. Diabetes Obes Metab. 2008;10:376-386.

40. Hollander P, Li J, Allen E, Chen R. Saxagliptin added to a thiazolidinedione improves glycemic control in patients with type 2 diabetes and inadequate control on thiazolidinedione alone. J Clin Endocrinol Metab. 2009;94:4810-4819.

41. Patel C, Castaneda L, Frevert U, Li L, Kornhauser DM, Boulton DW. Single-Dose Pharmacokinetics and Safety of Saxagliptin in Subjects with Hepatic Impairment Compared with Healthy Subjects. Diabetes Care. 2008;57 Suppl 1:537.

42. Ahren B, Schweizer A, Dejager S, et al. Vildagliptin enhances islet responsiveness to both hyper- and hypoglycemia in patients with type 2 diabetes. J Clin Endocrinol Metab. 2009;94:1236-1243.

43. Wolf R, Frederich R, Fiedorek F, et al. Evaluation of CV Risk in the Saxagliptin Clinical Trials. Diabetes. 2009;59 Suppl 1:8-LB.

44. Gallwitz B, Häring HU. Future perspectives for insulinotropic agents in the treatment of type 2 diabetes-DPP-4 inhibitors and sulphonylureas. Diabetes Obes Metab. 2010;12:1-11.

45. Traynor K. FDA approves saxagliptin for type 2 diabetes. Am J Health Syst Pharm. 2009;66:1513.

Diabetes, Metabolic Syndrome and Obesity: Targets and Therapy

Dovepress

\section{Publish your work in this journal}

Diabetes, Metabolic Syndrome and Obesity: Targets and Therapy is an international, peer-reviewed open-access journal committed to the rapid publication of the latest laboratory and clinical findings in the fields of diabetes, metabolic syndrome and obesity research. Original research, review, case reports, hypothesis formation, expert opinion and commentaries are all considered for publication. The manuscript management system is completely online and includes a very quick and fair peer-review system, which is all easy to use. Visit http://www.dovepress.com/testimonials.php to read real quotes from published authors. 